\title{
Surface temperature response to regional black carbon emissions: do lo- cation and magnitude matter?
}

Maria Sand et al.

Correspondence to: Maria Sand (maria.sand@cicero.oslo.no)

The copyright of individual parts of the supplement might differ from the CC BY 4.0 License. 


\section{Supplementary figures}

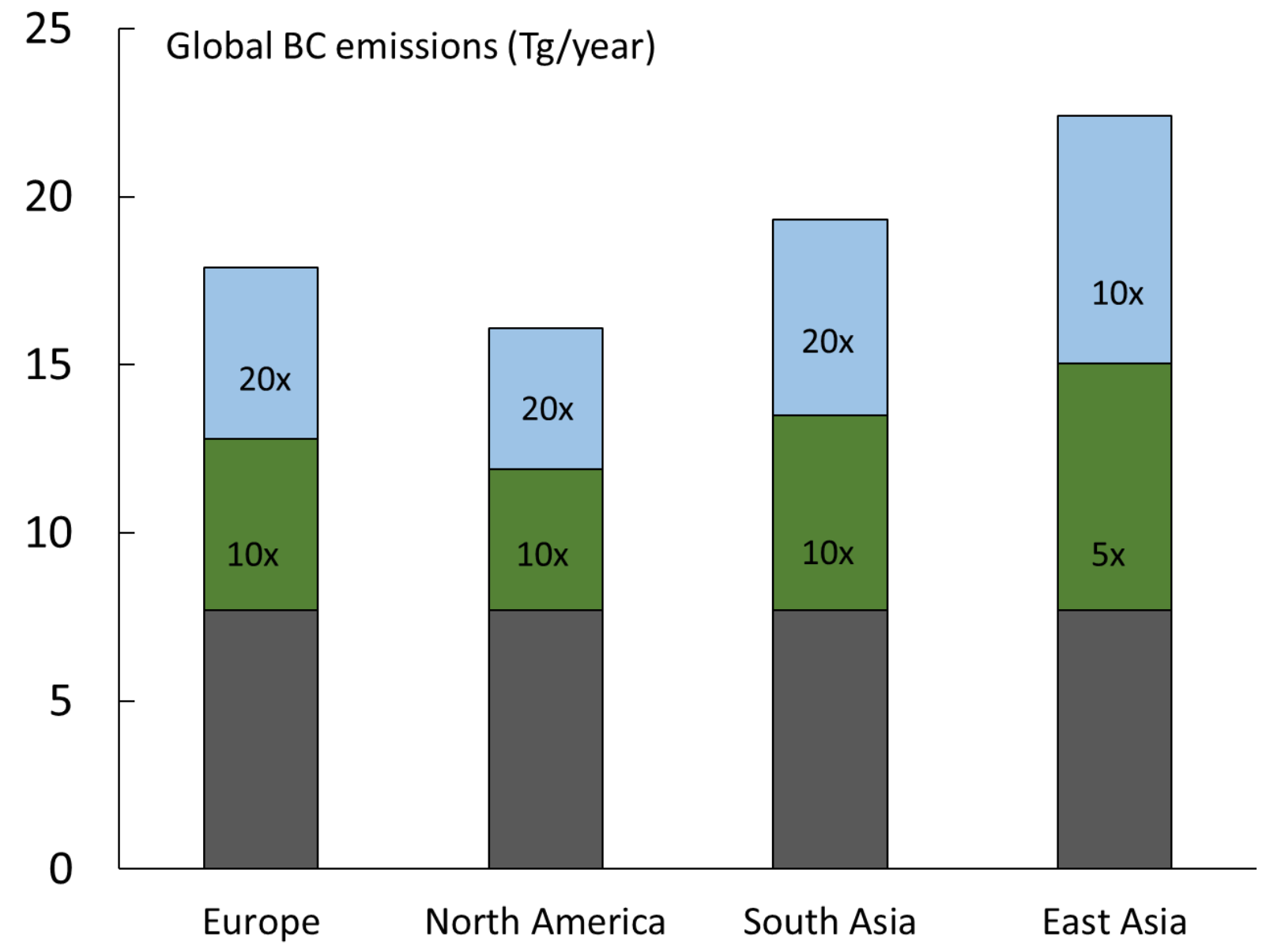

Figure S1: Global BC emissions (in Tg/yr). Grey bars represent the baseline emissions. Green bars represent the added increase in global $\mathrm{BC}$ emissions for the lowest emission rates $(10 \times \mathrm{BC}$ emissions for Europe, North America and South Asia, and $5 \times \mathrm{BC}$ emissions in East Asia), i.e. total global emissions are then grey+green bars. Total height of the bars (grey+green+blue) represent the global $\mathrm{BC}$ emissions for the highest emission rates $(20 \times \mathrm{BC}$ emissions for Europe, North America and South Asia, and 10×BC emissions in East Asia). 


\section{$\mathrm{ERF}\left[\mathrm{W} / \mathrm{m}^{2}\right]$}
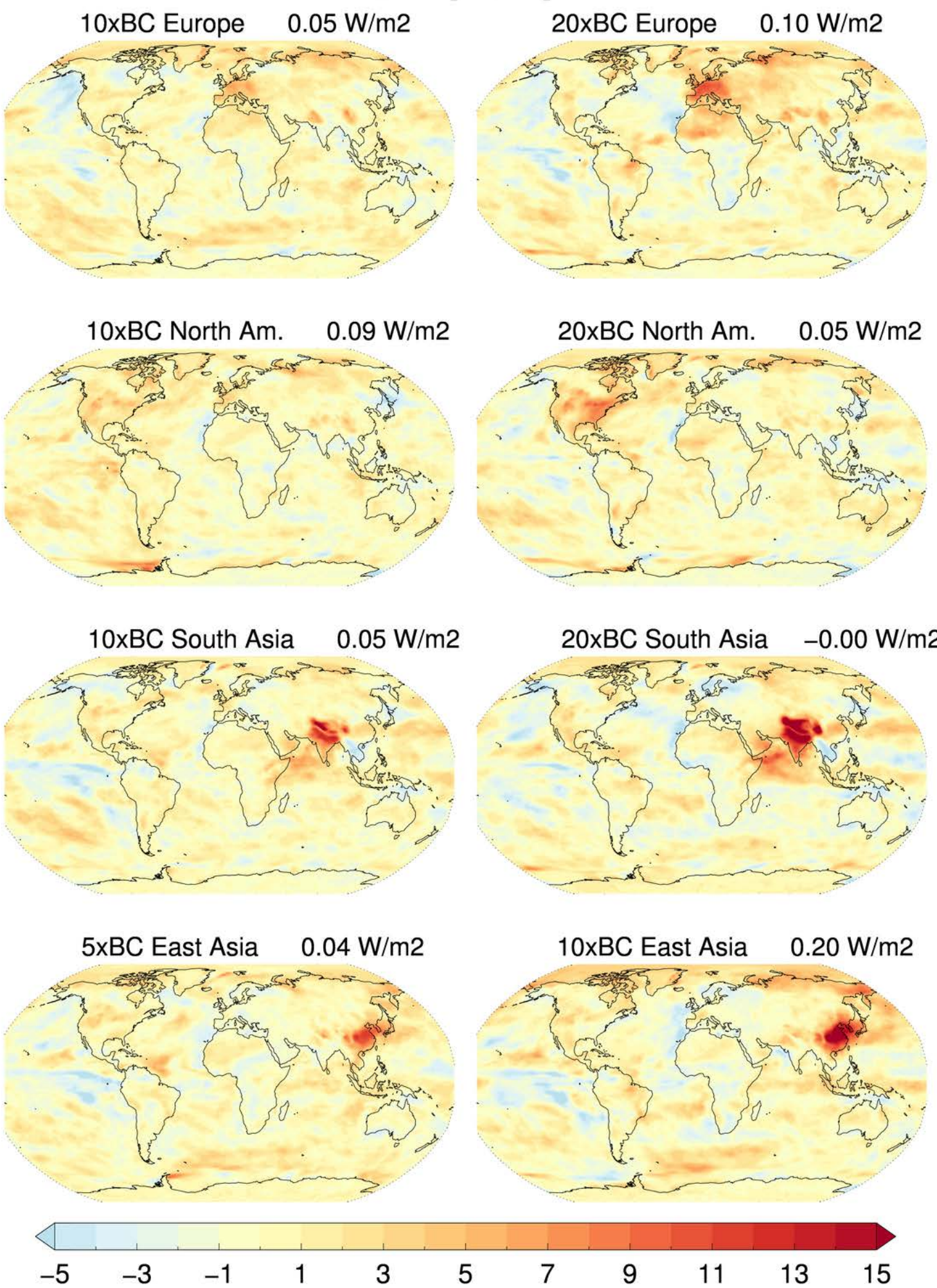

Figure S2: Effective radiative forcing (in $\mathrm{Wm}^{-2}$ ) to $\mathrm{BC}$ emissions perturbations. The emission location (Europe, North America, South Asia, East Asia) is given on top of each plot. In the right-side column the emission rate is doubled compared to the left-side column. 
$\mathrm{BC}$ concentrations [ug/ $\left.\mathrm{m}^{3}\right]$ normalized to emissions [ $\left.\mathrm{Tg} / \mathrm{yr}\right]$ Europe
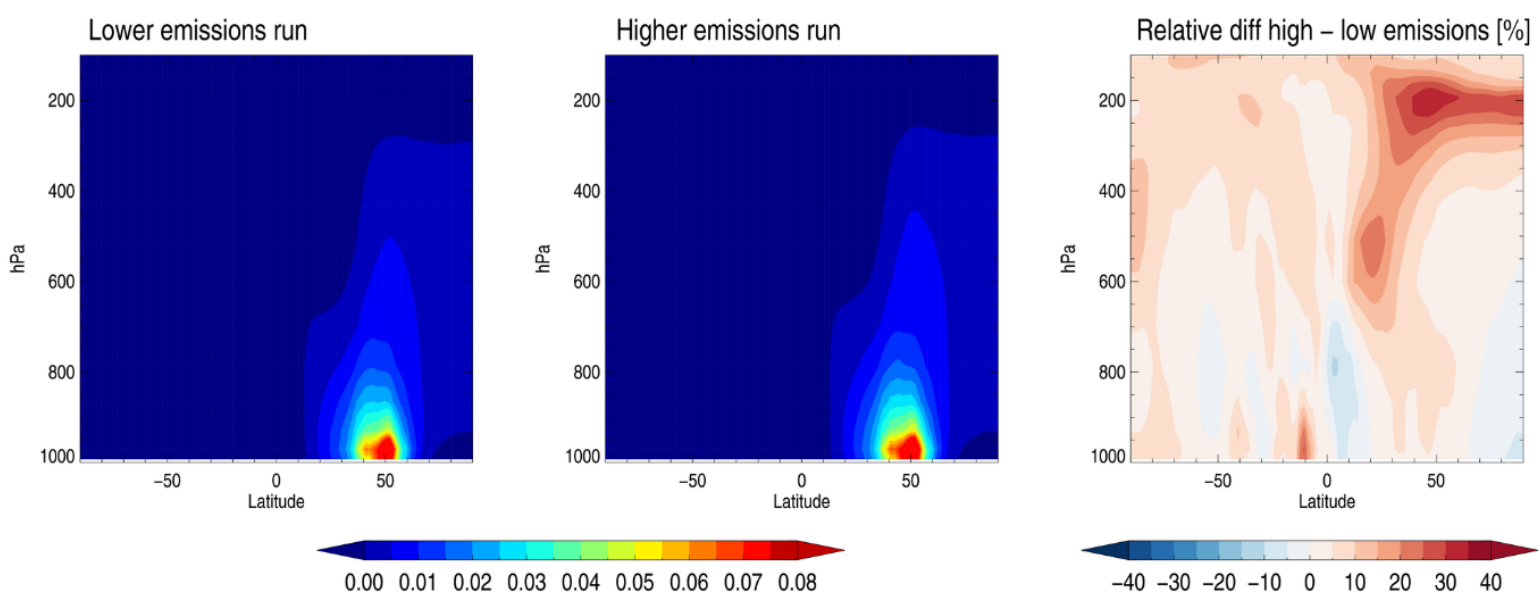

Figure S3: Zonal mean BC concentrations normalized to emissions for European emission perturbations.

BC concentrations $\left[\mathrm{ug} / \mathrm{m}^{3}\right]$ normalized to emissions [Tg/yr] North_America
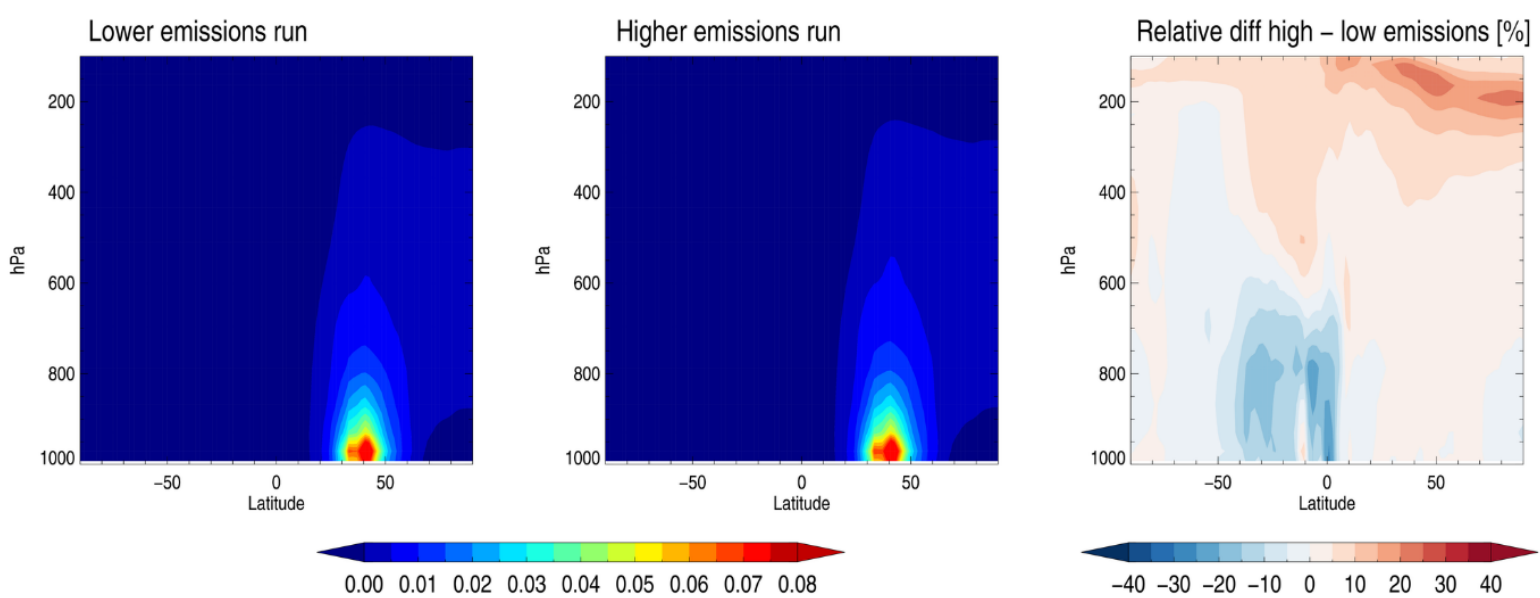

Figure S4: As S3, but for North American emission perturbations.

$\mathrm{BC}$ concentrations [ug/ $\left./ \mathrm{m}^{3}\right]$ normalized to emissions [Tg/yr] East_Asia
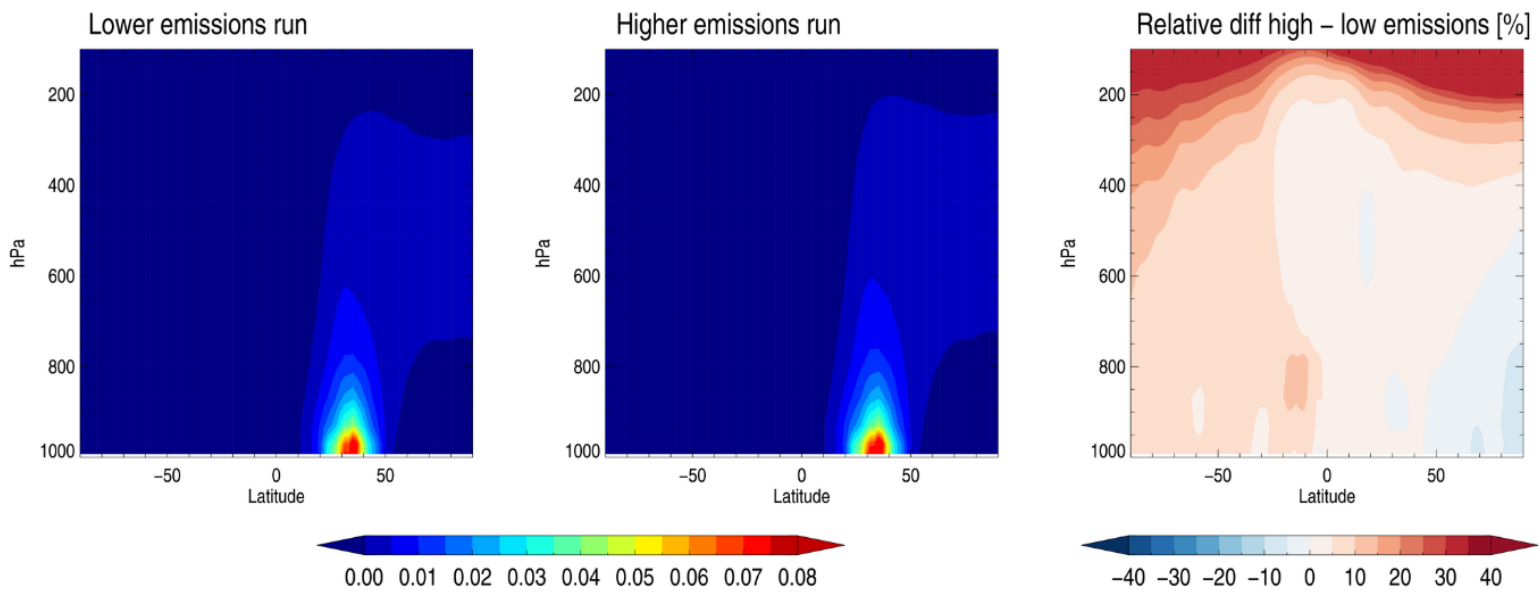

Figure S5: As S3, but for East Asian emission perturbations. 
BC concentrations $\left[\mathrm{ug} / \mathrm{m}^{3}\right]$ normalized to emissions [Tg/yr] South_Asia
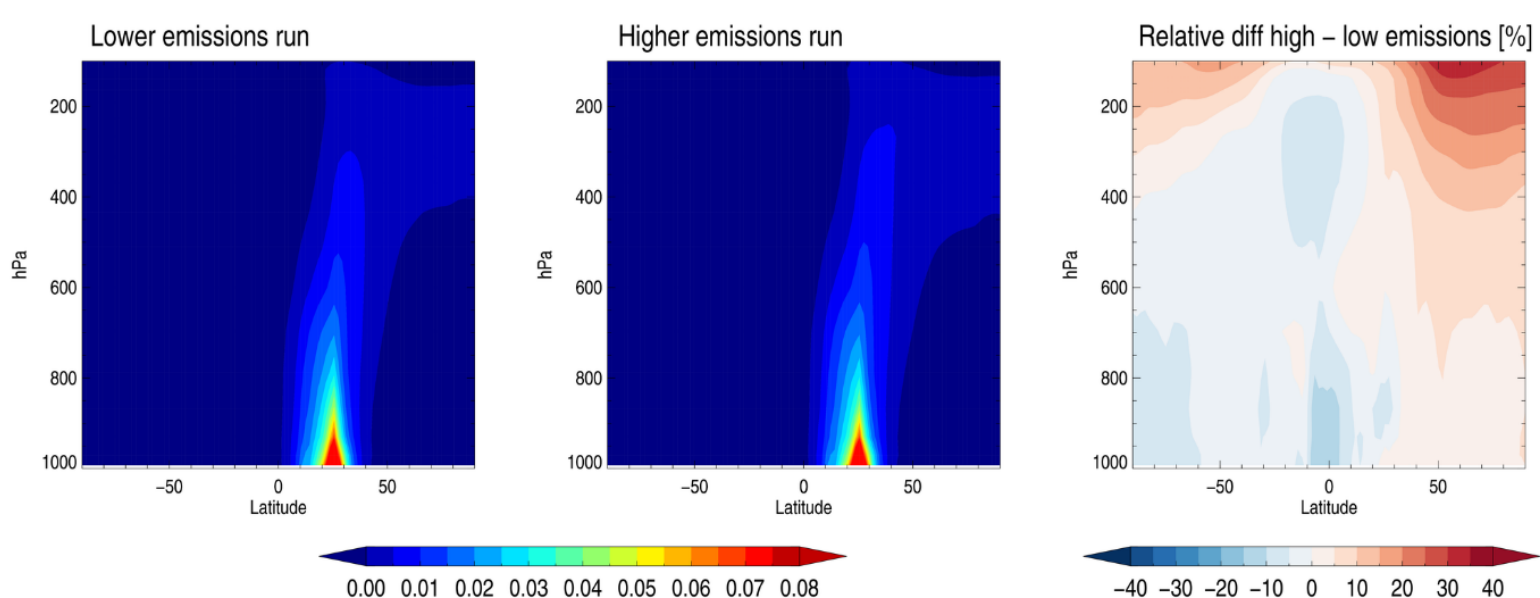

Figure S6: As S3, but for South Asian emission perturbations. 